İş ve İnsan Dergisi I The Journal of Human and Work

Y1l | Year: Ekim | October 2019

Cilt-Say1 | Volume-Issue: 6 (2)

ss I pp: 133-143

doi: 10.18394/ iid.504889

e-ISSN 2148-967X

http://dergipark.gov.tr/iid/

Araştırma Makalesi

\title{
Dönüştürücü Liderliğin İş Becerikliliği Üzerindeki Etkisi: Akademisyenler Üzerinde Bir Uygulama
}

\author{
The Effect of Transformational Leadership on Job Crafting:
}

A Study on Academic Personnel

Gökhan Kerse ${ }^{a}$, Mustafa Babadăg ${ }^{b}$

\section{MAKALE BİLGİSI}

Anahtar Kelimeler:

Dönüştürücü Liderlik, $\dot{I S S ̧}_{\text {S }}$

Becerikliliği, Görev

Becerikliliği, Bilissel

Beceriklilik, İlişkisel

Beceriklilik

Tarihler:

Geliş 28 Aralık 2018

Düzeltme geliş 23 Mayıs

2019

Kabul 28 Mayıs 2019

\section{ARTICLE INFO}

\section{Keywords:}

Transformational

Leadership, Job Crafting

Task Crafting, Cognitive

Crafting, Relational Crafting

Article history:

Received 28 December 2018

Received in revised form 23

May 2019

Accepted 28 May 2019
ÖZ

Günümüzün rekabet dünyasında örgütleri başarlya ulaştıracak faktörler arasında çalı̧̧anlar önemli bir yere sahiptir. Özellikle çalışanların proaktif davranışlarının bu konudaki katkısı yadsınamaz. Bu nedenle proaktif davranış olarak değerlendirilen iş becerikliliği kavramı bu araştırmanın çalışma konusunu oluşturmakta ve bu kapsamda da dönüşürücü liderliğin iş becerikliliği üzerindeki etkisi değerlendirilmeye çalışılmaktadır. Bu değerlendirmeyi yapabilmek için 138 akademik personelden anket yöntemi ile veri toplanmıs ve veriler istatistiki paket programlarl ile analiz edilmiştir. Analizler sonucunda dönüștürücü liderliğin iş becerikliliğini pozitif yönde ve anlamlı olarak etkilediği tespit edilmiştir. Ayrıca dönüşürü̈cü liderliğin iş becerikliliğinin alt boyutlarını da (görev becerikliliği, bilișsel beceriklilik ve ilișkisel beceriklilik) pozitif yönlü ve anlamlı olarak etkilediği sonucuna ulaşılmıştır.

${ }^{a}$ Dr. Öğr. Üyesi, Karamanoğlu Mehmetbey Üniversitesi, ÏIBF, İşletme Bölümü, Karaman, Türkiye. E-mail: gokhankerse@hotmail.com. ORCID: 0000-0002-1565-9110

b İletişim kurulacak yazar, Öğr. Gör. Dr., Muğla Sitkı Koçman Üniversitesi, Muğla Meslek Yüksekokulu, Dış Ticaret Bölümü, Muğla, Türkiye.E-mail: mustafababadag@mu.edu.tr.ORCID: 0000-0002-0198-7105 


\section{GíRiş}

Burns (1978) ile literatürde yer alan dönüştürücü liderlik, o günden bugüne psikoloji, sosyoloji, eğitim, sağllk ve yönetim olmak üzere birçok alanda popüler olmuştur. Söz konusu bu popülerlik, ilgili alanlarda dönüştürücü liderliğe ilişkin gerek kavramsal gerekse ampirik çalışmaların yaygınlaşmasını sağlamıştır. Literatürde kavramın çalışanların bireysel ve örgütsel tutum ve davranışlarında (çıktılarda) olumlu değişim ve dönüşümler ortaya çıkardığı öne sürülmüş ve görgül araştırmalarla dönüştürücü liderliğin olumlu sonuçları belirlenmeye çalışılmıştır. Zira yapılan araştırmalarda dönüştürücü liderliğin öz-yeterliliği (Cavazotte, Moreno \& Bernardo, 2013) ve psikolojik sermaye algısını artırdığı (Wang, Zheng \& Zhu, 2018); iş stresi ve tükenmişliği ise düşürdüğü (Salem, 2015) belirlenmiştir. Ayrıca araştırmalar bu liderlik şeklinin işe ilişkin tatmini (Abelha, Carneiro \& Cavazotte, 2018) ve bağlılığ1 (Ding, Li, Zhang, Sheng \& Wang, 2017) güçlendirdiğini, örgüte ilişkin bağlılığı (El Kordy, 2013) ve vatandaşlık davranışlarını artırdığını (Soo Young, 2017); etik iklim algısı oluşturarak işe yabancılaşmayı ise azalttığını (Babadağ \& İşcan, 2017) tespit etmiştir. $\mathrm{Bu}$ araştırmada ise dönüştürücü liderliğin olası bir diğer olumlu çıktısı olarak çalışanların işlerinde değişimler yapma (iş becerikliliği) davranışı ele alınmıştır. Araştırma “Akademik personelin dönüştürücü liderlik algısı ve iş becerikliliği düzeyi nedir? Akademik personelin dönüştürücü liderlik algısı, işlerini kişisel ilgi ve yeteneklerine göre değiştirmesinde (iş becerikliliği) belirleyici midir?" sorularını cevaplamaya çalışmıştır. Konuyla ilgili literatürde gerekli incelemeler yapılmış ve akademik personel üzerinde iş becerikliliği kavramının ele alınmadığı görülmüştür. Öte yandan incelemelerde dönüştürücü liderliğin iş becerikliliği ile ilişkisini ele alan uluslararası çalışmaların oldukça sınırlı olduğu (Hetland, Hetland, Bakker \& Demerouti, 2018; Wang, Demerouti \& Le Blanc, 2017), ulusal alanda ise araştırma bulunmadığı görülmüştür. Ayrıca uluslararası söz konusu çalışmalarda dönüştürücü liderlik ile iş becerikliliği davranışının bu araştırmada ele alınan boyutlar ile incelenmediği belirlenmiştir. Araştırmanın ifade edilen bu önemi nedeniyle literatüre katkı sağlayacağ düşünülmektedir.

\section{KAVRAMSAL ÇERÇEVE VE HIPOTEZLER}

Dönüştürücü liderlik kavramı literatüre Burns (1978) tarafından kazandırılmıştır. Burns (1978) dönüştürücü liderliğin liderlerin ve takipçilerin birbirlerini daha yüksek ahlaki ve motivasyonel düzeye yükselttikleri bir süreç olduğunu öne sürmüştür (Ladan, Nordin \& Belal, 2017). Daha sonraki yıllarda dönüştürücü liderliği Bass (1985) ele almış ve kavramı geliştirerek günümüzdeki anlamıyla kullanılmasını sağlamıştır. Bass (1985) dönüştürücü liderliği; liderlerin çalışanlarını başlangıçta beklenenden daha fazlasını yapma ve ortak bir hedefe ulaşmak için takipçilerin kişisel çıkarlarını aşmalarını teşvik etme süreci olarak tanımlamıştır. Bass (1985)'a göre dönüştürücü bir lider takipçilerini grup, örgüt ve toplumun iyiliği için kendi kişisel çıkarlarının ötesine geçmeye motive etmekte (Muchiri, McMurray, Nkhoma \& Pham, 2019) ve grup ve örgüt amaçlarına ulaşılması için onları yönlendirmektedir.

Dönüştürücü liderlik takipçilerin değerlerini, normlarını ve ilgilerini değiştiren ve bu sayede başlangıçtaki performanslarının ötesine geçmesini sağlayan liderlik şeklidir (Aryee, Walumbwa, Zhou \& Hartnell, 2012). Bu liderlik şeklinde liderler çalışanın iş tanımında belirlenen beklentilerin ötesine geçmeleri için onları teşvik eder ve onlara ilham verir (Wang, Zheng \& Zhu, 2018). Onlar takipçilerinin gelişmeye ve değişmeye istekli olmasını sağlayarak (Eliophotou-Menon \& Ioannou, 2016) hedeflenen düzeyde örgütsel değişimlerin gerçekleştirilmesini sağlamaktadır (Iqbal, 2016). Bunu yaparken ise takipçilerin (çalışanların) kişisel ve mesleki isteklerini ve ihtiyaçlarını göz önünde bulundurmaktadır (Wang, Zheng \& Zhu, 2018).

Dönüştürücü liderlik çalışanların üyesi olduğu örgütün amaçlarına bağlılık oluşturması ve bu amaçlara ulaşmaları için güçlendirilmeleri sürecidir (Yukl, 1994). Dönüştürücü liderler güçlendirme faaliyetini iki şekilde gerçekleştirmektedir: Birincisinde dönüştürücü liderler yasal otoritelerini ve güçlerini takipçilerle paylaşmakta; dolayısıyla ilişkisel anlamda bir güçlendirme ortaya çıkmaktadır. İkincisinde dönüştürücü liderler çalışanları psikolojik olarak etkilemekte ve onların öz yeterlilik algılarını ortaya çıkarmakta; dolayısıyla güçlendirme motivasyonel olarak gerçekleşmektedir (Babadağ \& İşcan, 2017).

Dönüştürücü liderleri astların yüksek düzeyde performanslarını göz önüne alarak onları statükonun ötesinde dönüştüren ve astlar arasında etkileşimi destekleyen ve yenilikçi yeteneğin gelişmesini sağlayan liderler olarak da tanımlamak mümkündür (Tabassi, Roufechaei, Bakar \& Yusof, 2017). Dönüştürücü liderler, astlara kişisel çıkarlarının üzerinde örgüt çıkarlarını benimsetirler ve bu doğrultuda astları motive ederler (Abu Nasra \& Heilbrunn, 2016). Ayrıca astların kişisel gelişim ve içsel motivasyonlarına önem verdikleri için (Nazim 
\& Mahmood, 2016), astların örgütteki formal rol tanımlarında beklenenin ötesine geçmesini sağlarlar (Abu Nasra \& Heilbrunn, 2016).

Dönüştürücü liderler; takipçilerini idealleştirilmiş etki, ilham verici motivasyon, entelektüel uyarım veya bireyselleştirilmiş ilgi yoluyla kendi çıkarlarının ötesinde hareket ettiren liderlerdir (Ladan vd., 2017). Ídealleştirilmiş etki, dönüştürücü liderlerin hayranlık duyulan ve güvenilen bir rol model olarak hareket etmesini ifade eder (Reuvers, Van Engen, Vinkenburg \& Wilson-Evered, 2008). Ilham verici motivasyon, dönüştürücü liderlerin takipçilerin vizyonu paylaşmalarına ilham vererek yüksek beklentileri iletmelerini ve bu vizyona yönelik misyon duygusunu içselleştirmelerini sağlamalarını içerir (Abelha vd., 2018). Entelektüel uyarım, takipçilerin yenilikçi ve yaratıcı yollarla verilen görevleri farklı bir şekilde yapmalarını teşvik etmektir (Getachew \& Zhou, 2018). Son olarak bireyselleştirilmiş ilgi ise dönüştürücü liderlerin her bir astın farklılıklarını göz önünde bulundurarak onlara kişisel ilgi göstermesidir (Reuvers vd., 2008). Liderlerin söz konusu özellikleri kullanarak çalışanlarda dönüştürücü liderlik algısını oluşturması bireysel ve örgütsel birçok olumlu sonucun oluşmasını sağlamaktadır. Dönüştürücü liderlik algısının oluşmasıyla çalışanın öz-yeterliliği (Cavazotte vd., 2013), güçlendirme algısı, refahı ve yaşam anlamı artacak (Krishnan, 2012); iş tatmini ve örgütsel bağlılık güçlenecek (El Kordy, 2013), örgütsel vatandaşlık davranışları yaygınlaşacak (Soo Young, 2017) ve çalışan performansı yükselecektir (Rita, Payangan, Rante, Tuhumena \& Erari, 2018). Dönüştürücü liderlik algısının ortaya çıkmasıyla gerçekleşecek bir diğer olumlu çıktı çalışanın iş becerikliliği davranışıdır (Hetland vd., 2018).

Temeli iş tasarımı teorisine dayanan ve bu teoriden ortaya çıkan iş becerikliliği kavramı (Miller, 2015) çalışanların yaptıkları işte fiziksel, bilişsel ve ilişkisel olarak değişimler yapması ve işlerini kişisel özelliklerine uyumlu hale getirmesidir (Wrzesniewski \& Dutton, 2001). Çalışanlar işlerinde bu davranış ile işlerindeki sosyal çevreyi ve işin tasarımını ve işlerinin anlamlarını değiştirmek için harekete geçmektedir (Travaglianti, Babic \& Hansez, 2016). Dolayısıyla da söz konusu davranışların sergilenmesiyle çalışan işinde kontrolün kendisinde olduğunu hissetmekte, işi kavramakta ve iş arkadaşlarıyla daha etkili bağlantı kurmaktadır (Kerse, 2017).

İş becerikliliği çalışanların işlerini kişisel ilgi ve değerleri ile uyumlu hale getirmek amaciyla giriştikleri, dolayısıyla da işlerini yeniden tasarlama olanağına sahip oldukları informal bir süreci ifade eder (Kerse, 2018). Bu süreç ile çalışan yaptığı işte pasif bir unsur olmaktan kurtularak aktif bir faktör konumuna gelmekte (Kerse, 2017) ve işleriyle kişisel tutkuları, yetenekleri ve tercihleri arasında daha iyi bir uyum sağlamaktadır (Tims, Bakker \& Derks, 2015; Van Wingerden, Derks \& Bakker, 2017).

İş becerikliliği çalışanların işlerini yapma, işlerine görevler ekleme ve bırakma, görevleri tamamlama biçimlerini değiştirme ve işle ilgili faaliyetlerin sayısını değiştirme gibi değişiklikleri ifade etmektedir (Bizzi, 2017; Wang, Wang \& Li, 2018). $\mathrm{Bu}$ değişiklikler göreve, ilişkiye ve bilişe ilişkin çalışanın beceriklilik düzeyini yansıtmaktadır. Görev becerikliliğiyle çalışan işindeki görevlerin sayısını, kapsamını veya türünü değiştirerek işin görev sınırlarını düzenlerken; ilişkisel beceriklilikte işyerindeki diğerleriyle olan etkileşimin kalitesini veya miktarını değiştirerek işin ilişkisel yönlerinde düzenlemeler yapmaktadır. Bilişsel beceriklilikte ise işe ilişkin bakış açısı değişmekte (Zhang \& Parker, 2019) ve işe ilişkin algılar yeniden yapılanmaktadır (Kerse, 2018).

İș talepleri ve kaynaklarının proaktif olarak kişiselleştirilmesi olarak da tanımlanabilen iş becerikliliği, çalışanların tercihlerine uygun olarak iş çevresini ayarlamasına olanak sağlar. Bireysel olarak kişiselleştirilmiş bir çalışma ortamı, çalışanın işyerinde enerjik ve kendini adamış hissetmesini sağlar (Mäkikangas, 2018). İş becerikliliği sayesinde çalışanlar iş rollerinin görev ve sosyal yönlerinde proaktif revizyonlar yaparak (Dierdorff \& Aguinis, 2018) kendileri için daha olumlu veya kendine daha uyumlu bir iş kimliği yaratırlar (Slemp, 2016).

Daha önce de ifade edildiği gibi dönüştürücü liderler çalışanların iş tanımının ötesine geçmeleri için onları teşvik eden ve onlara ilham veren liderlerdir (Wang, Zheng \& Zhu, 2018). Söz konusu bu teşvik ve ilham çalışanların işlerinde proaktif iş davranışlarını artırmaktadır (Schmitt, Den Hartog \& Belschak, 2016). İş becerikliliğinin de görev tanımlarının ötesinde proaktif bir davranış olduğu dikkate alınırsa (Grant \& Ashford, 2008), dönüştürücü liderlik algısıyla iş becerikliliği davranışının teşvik edileceği ve çalışanların işlerinde değişimler gerçekleştirebileceği beklentisi ortaya çıkabilir. Literatürde söz konusu beklentiye ilişkin sadece iki (2) çalışma yer almaktadır. Bunlardan birisi Wang ve arkadaşları (2017) tarafindan Hollanda'da ast ve üst pozisyonlu çalışanlar üzerinde yapılmış ve dönüştürücü liderliğin uyumluluk aracılığıyla iş becerikliliği ile etkileşimli olduğu öne sürülmüştür. Bir diğer araştırmada Hetland ve arkadaşları (2018) Norveç'te finans, eğitim, kamu yönetimi ve danışmanlık işletmeleri üzerinde çalışmalarını 
gerçekleştirmiş ve günlük düzeyde dönüştürücü liderlik algısı ile günlük düzeyde iş becerikliliğinin pozitif yönde iliş̧kili olduğunu belirlemiştir.

$\mathrm{Bu}$ teorik gerekçeler ve bulgular doğrultusunda aşağıdaki hipotez(ler) oluşturulmuştur:

H1: Dönüştürücü liderlik algısı çalışanların iş becerikliliği davranışını pozitif yönde etkiler.

Hla: Dönüştürücü liderlik algısı çalışanların görev becerikliliği davranışını pozitify yönde etkiler.

H1b: Dönüştürücü liderlik algısı çalışanların bilişsel beceriklilik davranışını pozitif yönde etkiler.

H1c: Dönüştürücü liderlik algısı çalışanların ilişkisel beceriklilik davranışını pozitif yönde etkiler.

\section{ARAŞTIRMA}

\section{Araştırmanın Amacı, Örneklemi ve Ölçüm Aracı}

$\mathrm{Bu}$ araştırmanın amacı dönüştürücü liderliğin iş becerikliliği üzerinde anlamlı bir etkiye sahip olup olmadığını belirlemektir. Başka bir ifade ile araştırmada dönüştürücü liderlik algılayan çalışanlar işlerinin kapsamında veya sınırlarında bir değişiklik yaratıyorlar mı? Sorusuna cevap aranmaktadır. Bu amaca bağlı olarak anket formu hazırlanmış ve bir üniversitede çalışan 138 akademisyenden kolayda örnekleme yöntemi ile veri toplanmıştır. Anket formunda kullanılan değişkenlere ait ölçekler daha önce kullanılmış; güvenilirliği ve geçerliliğ̣i kanıtlanmış ilgili ölçeklerden elde edilmiştir. Ayrıca ankette değişkenlere ait ölçeklerin cevaplanmasında beşli Likert derecelendirmesi (1- Kesinlikle Katılmıyorum, 2- Katılmıyorum, 3- Kararsızım, 4Katıliyorum, 5- Kesinlikle Katıliyorum) kullanılmıştır. Anket formu ise üç bölümden oluşmaktadır.

Anketin birinci bölümünde çalışanların demografik özellikleri ile ilgili sorular bulunmaktadır. Demografik ifadelere 138 katılımeının vermiş olduğu yanıtlar değerlendirildiğinde şu sonuçlara ulaşılmıştır. Katılımcıların cinsiyetleri bakımından dağılımında \%73,9'luk kısmı erkekler oluşturmaktadır. Medeni durumları bakımından dağılımında ise \%58,7'lik kısmı evli katılımcılar oluşturmaktadır. Katılımcıların yaşlarına bakıldığında ise katılımcılardan 26-35 yaş aralığında olanların $\% 53,6$ ile çoğunluğu oluşturduğu belirlenmiştir. Katılımcıların eğitim durumları değerlendirildiğinde ise lisansüstü mezunların $\% 57,2$ ile en yüksek oranı oluşturduğu tespit edilmiştir. Ayrıca katılımcıların \%59,4'ünün 7 yıl veya daha uzun süredir iş hayatında olduğu belirlenmiştir.

Anketin ikinci bölümünde ise, çalışanların iş becerikliliği davranışını ölçmek için Slemp ve Vella-Brodrick (2013) tarafindan geliştirilen iş becerikliliği ölçeğinden yararlanılmıştır. Ölçek 19 ifadeden ve 3 alt boyuttan oluşmaktadır. Ölçeği geliştiren araştırmacılar iş becerikliliği ölçeğinin alt boyutlarını görev becerikliliği, bilişsel beceriklilik ve ilişkisel beceriklilik olarak isimlendirmişlerdir. Ölçeğin Türkçe uyarlamasını ise Kerse (2017) gerçekleştirmiş ve araştırmacı ölçeğin Türkçe haliyle de güvenilir ve geçerli olduğunu tespit etmiştir.

Anketin üçüncü bölümünde ise, çalışanların dönüştürücü liderlik algılarını ölçmek için Bass (1985) tarafindan geliştirilen çok faktörlü liderlik (The Multifactor Leadership Questionnaire - MLQ) ölçeğinde yer alan dönüştürücü liderlik ifadelerinden yararlanılmıştır. Ölçek, Babadağ ve İşcan (2017)'ın çalışmalarında 7 ifade ve tek boyut olarak belirlenmiş ve bu araştırmada da bu şekliyle kullanılmıştır.

\section{Ölçeklere İlișkin Faktör Analizi ve Güvenilirlik Analizi Bulgulart}

Araştırmada ilk olarak ölçeklerin yapı geçerliliği ve temel boyutları belirlenmeye çalışılmış ve bu kapsamda da açımlayıcı faktör analizinden yararlanılmıştır. Açımlayıcı faktör analizinde madde faktör yüklerinin 0,40 'dan düşük olmaması, örneklem yeterlilik ölçütünü gösteren KMO (KaiseMeyer-Olkin Measure of Sampling Adequacy) değerinin 0,60 'dan yüksek olması ve verilerden anlamlı faktörler çıkacağını gösteren küresellik derecesinin (Barlett's Test of Sphericity) 0,05'den düşük değer alması beklenmektedir.

Araştırmada bu değerler dikkate alınarak ilk olarak iş becerikliliği ölçeğine açımlayıcı faktör analizi uygulanmıştır. Analiz sonucunda ölçeğin KMO değerinin 0,815 olduğu, anlamlllık düzeyinin ise ,000 olduğu belirlenmiştir. $\mathrm{Bu}$ değerler verilerin faktör analizine uygun olduğunu göstermektedir. $\mathrm{Bu}$ sonuca bağlı olarak ölçeğin faktör yapısına bakılmış ve ölçek maddelerinin üç alt boyutta toplandığı tespit edilmiştir. Ayrıca elde edilen üç faktörlü yapının toplam varyansın \%74,23'ünü açıkladığı ve ölçek maddelerinin faktör yüklerinin 0,915 ile 0,735 arasında değiş̧tiği sonucuna ulaşılmıştır. $\mathrm{Bu}$ sonuçlar maddelerin ait oldukları faktörü kabul edilebilir düzeyde açıkladığını ortaya koymakta ve ölçeğin Türkçe ifadelerle de orijinal halindekine benzer olduğunu ifade etmektedir. 
Açımlayıcı faktör analizi ile iş becerikliliği ölçeğinin faktör yapısı belirlendikten sonra belirlenen 3 boyutlu yapının doğrulayıcı faktör analizi ile sağlaması yapılmaya çalışılmıştır. Doğrulayıc1 faktör analizinde maddelerin standardize edilmiş regresyon yüklerinin 0,40 'tan düşük olmaması beklenmektedir. Ancak yapılan analizde bazı maddelerin standardize edilmiş regresyon yüklerinin 0,40 'tan düşük olduğu belirlenmiş ve bu nedenle İşB3, İşB10, İşB14, İşB16 ve İşB17 maddeleri modelden çıkarılmış ve analiz tekrardan yapılmıştır. Maddeler çıkarıldıktan sonra yapılan analiz bulguları Şekil 1'de gösterilmiştir.

İlgili maddeler çıkarıldıktan sonra ölçeğin uyum iyiliği değerlerine bakılmış ve ölçeğin gerekli değerleri sağladığı sonucuna ulaşılmıştır. İş becerikliliği ölçeğinin 3 boyutlu yapısını doğrulayan uyum iyiliği değerleri referans değerleri ile birlikte Tablo 1'de verilmiştir.
İş becerikliliği ölçeğinin faktör yapısı belirlendikten sonra dönüştürücü liderlik ölçeğine açımlayıcı faktör analizi uygulanmıştır. Analiz sonucunda ölçeğin KMO değerinin 0,869 olduğu, anlamlılık düzeyinin ise ,000 olduğu belirlenmiştir. $\mathrm{Bu}$ değerler verilerin faktör analizine uygun olduğunu göstermektedir. $\mathrm{Bu}$ sonuca bağlı olarak ölçeğin faktör yapısına bakılmış ve ölçek maddelerinin tek boyutta toplandığı tespit edilmiştir. Ayrıca, elde edilen tek faktörlü yapının toplam varyansın \%65,57'sini açıkladığ 1 ve ölçek maddelerinin faktör yüklerinin 0,856 ile 0,725 arasında değiştiği sonucuna ulaşılmıştır. $\mathrm{Bu}$ bulgulara dayanarak maddelerin ait olduğu faktörü kabul edilebilir düzeyde açıkladığı söylenebilir.

Dönüştürücü liderlik ölçeğine de iş becerikliliği ölçeğinde olduğu gibi açımlayıcı faktör analizinden sonra doğrulayıcı faktör analizi uygulanmış ve ölçeğin yapısı doğrulanmaya çalışılmıştır. Yapılan analiz sonucunda DL4 maddesinin standardize

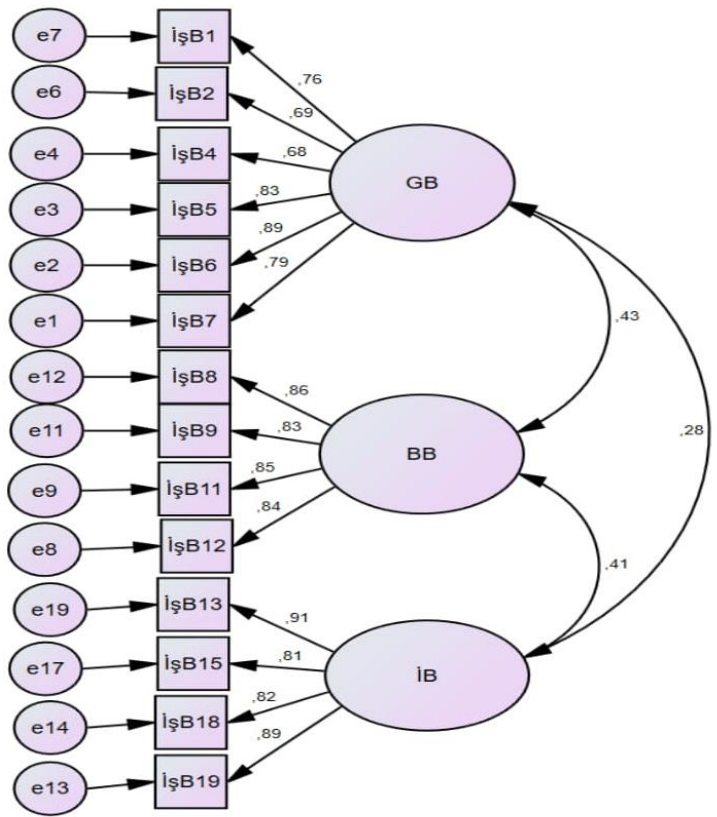

Şekil 1: İş Becerikliliği Ölçeğine İlişkin Doğrulayıcı Faktör Analizi

(GB: Görev Becerikliliği, BB: Bilişsel Beceriklilik, İB: İlişkisel Beceriklilik)

Tablo 1: İş Becerikliliği Ölçeğinin Uyum İndekslerine İlişkin Değerler

\begin{tabular}{lll}
\hline İndeksler & Referans Değeri & Ölçüm Model \\
\hline CMIN/DF & $0<\chi 2 /$ sd $\leq 5$ & 1,803 \\
\hline RMR & $\leq, 10$ &, 032 \\
\hline CFI & $\geq, 90$ &, 955 \\
\hline IFI & $\geq, 90$ &, 955 \\
\hline TLI & $\geq, 90$ &, 944 \\
\hline RMSEA & $<, 05-\leq, 08$ &, 077 \\
\hline
\end{tabular}


edilmiş regresyon yükünün 0,40 'tan düşük olduğu belirlenmiş bu nedenle ilgili madde modelden çıkarılarak analiz tekrardan gerçekleştirilmiştir. Ayrıca, modelde bazı indekslerin uyum değerlerinin gerekli ölçütü sağlamadığ́ gözlenmiş ve DL1 ile DL5 maddeleri arasında modifikasyon yapıldığ takdirde uyum değerlerinin iyileşeceği belirlenmiştir. $\mathrm{Bu}$ nedenle ilgili maddeler arasında modifikasyon yapılmıştır. Dönüştürücü liderlik ölçeğine ilişkin modifikasyon sonucu elde edilen standardize regresyon yükleri bulguları Şekil 2'de gösterilmiştir.

Dönüştürücü liderlik ölçeğine ilişkin modifikasyon sonrası elde edilen uyum iyiliği değerleri ise Tablo 2'de sunulmuştur.

Tablo 2'deki bulgular dönüştürücü liderlik ölçeğinin modifikasyon sonrası gerekli ölçütleri sağladığını ve faktör yapısının doğrulandığını göstermektedir.

Araştırmada daha sonra cronbach alpha katsayısı ile ölçeklerin içsel tutarlılıklarına bakılarak değişkenleri ölçen ifadelerin güvenilirlikleri değerlendirilmeye çalışılmıştır. Ölçeklerin güvenilir olarak kabul edilebilmesi için cronbach alfa katsayısının 0,70 ve üzerinde olmas1 gerekmektedir (Morgan, Leech, Gloeckner \& Barrett, 2004: 122). $\mathrm{Bu}$ referans değeri dikkate alınarak yapılan analiz sonucunda iş becerikliliği $(0,885)$ ve dönüştürücü liderlik $(0,908)$ ölçeklerinin güvenilir olduğu saptanmıştır. Ayrıca, iş becerikliliği ölçeğinin alt boyutları olan görev becerikliliği $(0,898)$, bilişsel beceriklilik $(0,908)$ ve ilişkisel becerikliliğin de $(0,917)$ güvenilir olduğu belirlenmiştir.

\section{Araştırma Hipotezlerinin Testi}

Araştırmada geliştirilen hipotezlerin testi yapılmadan önce değişkenler arasındaki ilişkilerin yönünü ve gücünü tespit edebilmek amaciyla korelasyon analizinden yararlanılmıştır. Analiz bulguları ise Tablo 3'de gösterilmiştir. Ayrıca tabloda katılımcıların verdiği cevaplara ilişkin değişkenlerin ortalamalarına ve standart sapmalarına da yer verilmiştir.

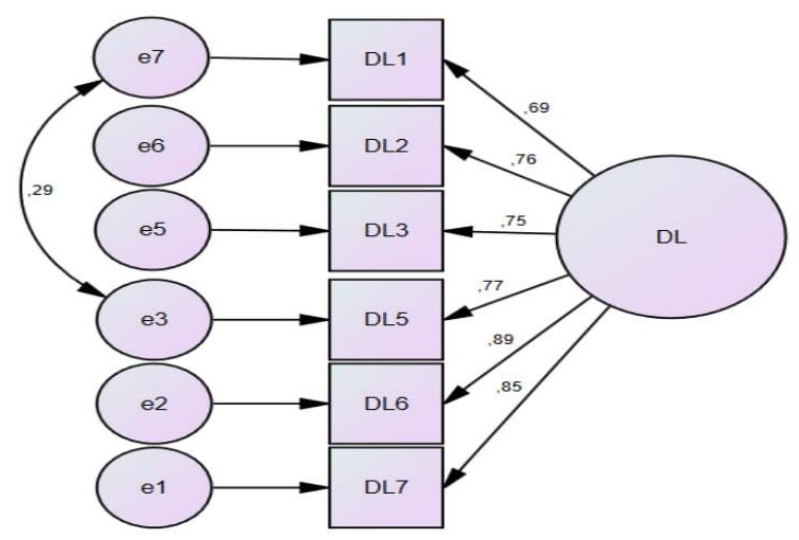

Şekil 2: Dönüştürücü Liderlik Ölçeğine İlişkin Doğrulayıcı Faktör Analizi

(DL: Dönüştürücü Liderlik)

Tablo 2: Dönüştürücü Liderlik Ölçeğinin Uyum İndekslerine İlişsin Değerler

\begin{tabular}{lll}
\hline İndeksler & Referans Değeri & Ölçüm Model \\
\hline CMIN/DF & $0<\chi 2 /$ sd $\leq 5$ & 1,308 \\
\hline RMR & $\leq, 10$ &, 013 \\
\hline CFI & $\geq, 90$ &, 995 \\
\hline IFI & $\geq, 90$ &, 995 \\
\hline TLI & $\geq, 90$ &, 991 \\
\hline RMSEA & $<, 05-\leq, 08$ &, 047 \\
\hline
\end{tabular}


Tablo 3: Korelasyon Analizi Bulguları, Değişkenlere İlişkin Ortalamalar ve Standart Sapmalar

\begin{tabular}{llllllll}
\hline Faktörler & ORT. & SS & $\mathbf{1}$ & $\mathbf{2}$ & $\mathbf{3}$ & $\mathbf{4}$ & $\mathbf{5}$ \\
\hline 1-Dönüştürücü Liderlik & 3,957 &, 607 & 1 & & & & \\
\hline 2-İş Becerikliliği & 4,120 &, 568 &, $637^{* *}$ & 1 & & & \\
\hline 3-Görev Becerikliliği & 4,079 &, 687 &, $418^{* *}$ &, $768^{* *}$ & 1 & & \\
\hline 4-Bilişsel Beceriklilik & 4,331 &, 666 &, $515^{* *}$ &, $711^{* *}$ &, $379^{* *}$ & 1 & \\
\hline 5-İlişkisel Beceriklilik & 3,971 &, 972 &, $506^{* *}$ &, $742^{* *}$ &, $250^{\text {** }}$ &, 367 & 1 \\
\hline
\end{tabular}

Tablo 3'deki bulgulara bakıldığında araştırmaya katılan katılımcıların dönüştürücü liderlik algılarının ve iş becerikliliği davranıșlarının yüksek düzeyde olduğu anlaşılmaktadır. Değişkenler arasındaki ilişkinin yönüne ve gücüne bakıldığında ise dönüştürücü liderliğin iş becerikliliği ile aynı yönlü, orta düzeyde ve anlamlı bir ilişkiye sahip olduğu $(\mathrm{r}=0,637, \mathrm{p}<0,01)$ tablodan izlenmektedir. Başka bir ifade ile tabloda dönüştürücü liderlik algısı arttığında, katılımcıların iş becerikliliği davranışlarında da artış olduğu gözlenmektedir. Benzer bulgular dönüştürücü liderlik algısı ile iş becerikliliği boyutları arasında da bulunmakta ve dönüştürücü liderlik algısı ile görev becerikliliği, bilişsel beceriklilik ve ilişkisel beceriklilik arasında da aynı yönlü ve anlamlı ilişkilerin olduğu tabloda görülmektedir. Ayrıca dönüştürücü liderliğin iş becerikliliği boyutlarından bilişsel beceriklilik ile en güçlü ilişkiye $(r=0,515, p<0,01)$ sahip olduğu anlaşılmaktadır. $\mathrm{Bu}$ bulgulara dayanarak dönüştürücü liderliğin iş becerikliliği ve iş becerikliliğinin boyutları üzerinde etkilerinin olacağ 1 söylenebilir. Ancak korelasyon analizi değişkenler arasındaki ilişkinin sadece yönünü ve gücünü gösterdiği için korelasyon analizi sonucuna bakarak bu değerlendirmeyi yapmak yanıltıcı olabilir. $\mathrm{Bu}$ nedenle dönüştürücü liderliğin iş becerikliliği ve iş becerikliliğinin her bir alt boyutu üzerinde etkiye sahip olup olmadığını tespit etmek ve araştırma kapsamında oluşturulan hipotezleri test etmek amaciyla basit doğrusal regresyon analizi yapılmıştır. Regresyon analizinde ilk olarak dönüştürücü liderliğin iş becerikliliği üzerindeki etkisi daha sonra da iş becerikliliğinin boyutları üzerindeki etkisi değerlendirilmeye çalışılmıştır. Elde edilen sonuçlar ise Tablo 4'te gösterilmiştir.

Tablo 4'e bakıldığında dönüştürücü liderliğin iş becerikliliğini pozitif yönde ve anlamlı olarak etkilediği görülmektedir (beta $=0,596, \mathrm{p}<0,01$ ). Ayrıca dönüştürücü liderlik iş becerikliliğindeki değişimin \%40,2'ini açıkladığı tablodan anlaşılmaktadır. $\mathrm{Bu}$ bulguya göre çalışanın dönüştürücü liderlik algısı arttığında iş becerikliliğinde de artış olacağı söylenebilir. Bu açıdan H1 hipotezi kabul edilmiştir. Tabloya bakıldığında ulaşılan bir başka bulgu dönüştürücü liderliğin görev becerikliliğini de pozitif yönde ve anlamlı olarak etkilediğidir ( beta $=0,473, \mathrm{p}<0,01$ ). Bununla birlikte dönüştürücü liderlik görev becerikliliğindeki değişimin \%16,9'unu açıklamaktadır. Bu bulguya bağlı olarak da H1a hipotezi kabul edilmiştir. Tablodan izlenen bir başka bulgu ise, dönüştürücü liderliğin bilişsel becerikliliği de pozitif yönde ve anlamlı olarak etkilediğidir (beta $=0,565, \quad \mathrm{p}<0,01)$. Ayrıca dönüştürücü liderlik bilişsel beceriklilikteki değişimin \%26'sını açıklamaktadır. $\mathrm{Bu}$ bulguya bağlı olarak ise H1b hipotezi kabul edilmiştir. Son olarak tablo dönüştürücü liderliğin ilişkisel becerikliliği de pozitif yönde ve anlamlı olarak etkilediğini (beta $=0,811, p<0,01$ ) ve dönüştürücü liderliğin ilişkisel beceriklilikteki değişimin $\% 25,1$ 'ini açıkladığını göstermektedir. Bu sonuca göre H1c hipotezi kabul edilmiştir.

Tablo 4: Değişkenler Arasındaki Regresyon Analizi Bulguları

\begin{tabular}{ccccc}
\hline Bağımlı Değişken & İş Becerikliliği & $\begin{array}{c}\text { Görev } \\
\text { Becerikliliği }\end{array}$ & $\begin{array}{c}\text { Bilişsel } \\
\text { Beceriklilik }\end{array}$ & $\begin{array}{c}\text { İlişkisel } \\
\text { Beceriklilik }\end{array}$ \\
\hline $\begin{array}{c}\text { Bağımsız Değişken: } \\
\text { Dönüştürücü Liderlik }\end{array}$ & & & & \\
\hline$\beta$ &, 596 &, 473 &, 565 &, 811 \\
\hline $\mathrm{t}$ & 9,645 & 5,367 & 7,011 & 6,849 \\
\hline $\mathrm{p}$ &, 000 &, 000 &, 000 &, 000 \\
\hline $\mathrm{R}^{2}$ &, 406 &, 175 &, 265 &, 256 \\
\hline Düzeltilmiş $\mathrm{R}^{2}$ &, 402 &, 169 &, 260 &, 251 \\
\hline $\mathrm{F}$ & 93,025 & 28,803 & 49,149 & 46,906 \\
\hline
\end{tabular}




\section{TARTIŞMA VE SONUÇ}

Küreselleşme ve teknolojideki gelişmeler birçok alanda olduğu gibi örgüt yaşamında da hızlı değişimlerin yaşanmasına neden olmaktadır. $\mathrm{Bu}$ nedenle örgütler hayatta kalabilmek ve hedeflerini gerçekleştirebilmek için proaktif davranışlara sahip çalışanlara ihtiyaç duymaktadırlar. $\mathrm{Bu}$ sayede örgütler çevreden gelen taleplere daha kolay cevap verebilmektedirler (Wang, Wang \& $\mathrm{Li}, 2018$ ). Hatta çevrede gerekli değişimleri örgütler proaktif çalışanlar ile kendileri başlatabilirler. Bu nedenle örgütlerde çalışanların iş becerikliliği davranışlarını ortaya çıkaracak faktörlerin neler olduğunun araştırılması önemli olarak görülmektedir. İş becerikliliği kavramı daha önce belirtildiği gibi çalışanların işlerini kapsayan fiziksel, zamansal, duygusal, bilişsel ve / veya ilişkisel sınırları proaktif olarak değiştirmesi süreci şeklinde tanımlanmaktadır (Wrzesniewski, LoBuglio, Dutton \& Berg, 2013). Dönüştürücü liderlik ise daha önce ifade edildiği gibi takipçilerini beklenen performansın ötesinde hareket etmeye yönlendiren ve çalışanların proaktif davranmasına zemin hazırlayan bir liderlik tarzı olarak görülmektedir. Özellikle entelektüel uyarım ile dönüştürücü lider takipçileri güçlendirerek takipçilerin yaratıcılıklarını açığa çıkarmakta ve takipçierin örgüt içerisinde yeni yaklaşımlar geliştirmelerini sağlamaktadır (Babadağ \& İşcan, 2017). Ayrıca dönüştürücü lider koç veya mentor gibi hareket ederek her bir takipçinin gelişme ve başarma ihtiyacina önem vermektedir (Bass \& Riggio, 2006). $\mathrm{Bu}$ nedenle dönüştürücü liderliğin iş becerikliliği üzerinde pozitif yönlü etki oluşturacağı düşünülmektedir.

Araştırma sonucunda dönüştürücü liderliğin iş becerikliliği üzerinde pozitif yönlü ve anlamlı etkiye sahip olduğu belirlenmiştir. Başka bir ifade ile dönüştürücü liderlik algılayan çalışanların iş becerikliliği davranışında bulunduğu veya işin sınırlarında değişiklik yaptıkları tespit edilmiştir. Daha önce belirttiğimiz gibi uluslararası literatürde Wang ve arkadaşları (2017) ile Hetland ve arkadaşları (2018) yaptıkları araştırmalarda benzer sonuçlara ulaşmışlar ve dönüştürücü liderliğin iş becerikliliği üzerinde pozitif yönlü etkiye sahip olduğunu belirlemişlerdir. $\mathrm{Bu}$ açıdan ulaşılan bulgunun uluslararası literatürde yapılan çalışmalar ile tutarlılık gösterdiği belirtilebilir. Ulusal literatür açısından ise ulaşılan bu bulgu bir ilk olarak değerlendirilebilir. Ulusal literatürde iş becerikliliği kavramı yeni yeni tartışılmaya ve araştırılmaya başlanan bir konudur ve dönüştürücü liderlik ile iş becerikliliği arasındaki ilişkiyi araştıran bir çalışmaya ulusal literatürde rastlanılmamıştır. $\mathrm{Bu}$ açıdan ulaşılan sonuç ulusal yazın açısından önemli olarak değerlendirilebilir.

Araştırma sonucunda ulaştığımız bir başka bulgu ise dönüştürücü liderliğin iş becerikliliğinin boyutları (görev becerikliliği, bilişsel beceriklilik ve ilişkisel beceriklilik) üzerinde de pozitif yönlü ve anlamlı etkiye sahip olduğu yönündedir. Ulaşılan bu bulgu hem uluslararası hem de ulusal literatür açısından bir ilk olduğu söylenebilir. Uluslararası literatürde dönüştürücü liderlik ile iş becerikliliği arasındaki ilişkiyi araştıran çalışmaların iş becerikliliğini bu boyutları ile araştırma konusu yapmadığg görülmüştür. Ulusal literatürde ise daha önce bu değişkenleri araştırma konusu yapan herhangi bir çalışmaya rastlanmamıştır.

$\mathrm{Bu}$ açıklamaların dışında araştırmanın teorik açıdan literatüre önemli bir katkı sağladığı söylenebilir. İş becerikliliğinde liderin takipçilerinin proaktif davranışlarının farkında olmadığı ve iş becerikliliğinin aşağıdan yukarıya doğru gerçekleşen bir yaklaşım olduğu düşünülmektedir (Wrzesniewski \& Dutton, 2001). Ancak araştırma sonucunda ulaştığımız bulgular, liderlerin dönüştürücü liderlik davranışları sergileyerek iş becerikliliğini teşvik edebileceğini göstermiştir. Başka bir ifade ile araştırma, üstlerinin desteği sonucunda da çalışanların iş becerikliliği davranışında bulunabileceklerini göstermiştir.

Araştırma bulgularına dayanarak uygulamaya dönük çıkarımlarda da bulunulabilir. Çalışanlarının iş becerikliliklerini arttırmak isteyen örgütlerin dönüştürücü liderlik davranışlarına önem vermesi gerektiği söylenebilir. Bu kapsamda da liderler iş becerikliliği davranışlarının memnuniyetle karşılandığı güvenilir, açık ve destekleyici bir iklim oluşturmak için çalışanlara bireyselleştirilmiş destek sağlayabilirler (Wang vd., 2017). Ayrıca dönüştürücü liderlik becerilerinin, eylem (uygulama) odaklı yöntemlere dayanan eğitimlerle geliştirilebileceğine inanıldığ 1 (Schmitt vd., 2016) için örgüt yöneticileri dönüştürücü liderlik özelliklerini geliştirebilecekleri eğitim programlarına katılabilirler. Böylece yöneticiler, dönüştürücü liderlik davranışlarını öğrenerek hayata geçirebilirler ve çalışanların, işin kapsamında değişiklikler yaratabilmeleri için gerekli ortamın oluşmasına katkı sağlayabilirler. Bunun yanında örgütler, terfi uygulamalarında dönüştürücü liderlik özelliğini bir ölçüt olarak belirleyebilirler ve bu özelliğe sahip kişileri yönetici pozisyonlarında özellikle tercih edebilirler. Böylece örgüt yapısını dönüştürücü liderliğin ufkuyla şekillendirerek iş becerikliliği için gerekli şartları yaratabilirler.

Her çalışmada olduğu gibi bu çalışmanın da bazı sınırlılıkları bulunmaktadır. Araştırmanın ilk 
sinırlılığ1 çalışmanın tek bir örgütte gerçekleștirilmesidir. $\mathrm{Bu}$ nedenle araştırma sonucunda ulaşılan bulguları genelleyebilmek için bundan sonra yapılacak araştırmalara değişkenler arasındaki ilişkileri başka örgütlerde ve sektörlerde de araştırmaları önerilebilir. Araştırmanın kesitsel bir yöntem ile gerçekleştirilmiş olması ise ikinci sınırlılık olarak değerlendirilebilir. Kesitsel yöntemde veriler çalışanların bir anlık duygularını yansıtmakta ve çalışanların farklı zamanlardaki düşüncelerini göz ardı etmektedir. $\mathrm{Bu}$ nedenle gelecekte yapılacak araştırmalara boylamsal çalışmalar ile çalışmalarını gerçekleştirmeleri önerilebilir. Böylece değişkenler arasındaki ilişkilere yönelik daha güvenilir ve anlamlı sonuçlar elde edilebilir. Bunun dışında çalışanların iş becerikliliği davranışlarını etkileyebilecek örgüt kültürü, örgüt iklimi, çalışanların kişilik özellikleri gibi birçok faktör bulunmaktadır. Bu nedenle iş becerikliliği üzerinde sadece dönüştürücü liderliğin etkisini araștırmak bașka bir sınırlılık olarak değerlendirilebilir. Bundan sonra yapılacak araştırmalara bu değişkenlere farklı değişkenleri de ekleyerek araştırmalarını gerçekleştirmeleri iş becerikliliğini ortaya çıkarabilecek unsurların neler olabileceğinin daha iyi anlaşılabilmesi için önerilebilir.

\section{KAYNAKÇA}

Abelha, D. M., Carneiro, P. C. C. \& Cavazotte, F. S. C. N. (2018). Transformational Leadership and Job Satisfaction: Assessing the Influence of Organizational Contextual Factors and Individual Characteristic's. Review of Business Management, 20(4), 516-532.

Abu Nasra, M. \& Heilbrunn, S. (2016). Transformational Leadership and Organizational Citizenship Behavior in the Arab Educational System in Israel: The Impact of Trust and Job Satisfaction. Educational Management Administration \& Leadership, 44(3), 380-396.

Aryee, S., Walumbwa, F. O., Zhou, Q. \& Hartnell, C. A. (2012). Transformational Leadership, Innovative Behavior, and Task Performance: Test of Mediation and Moderation Processes. Human Performance, 25, $1-25$.

Babadağ, M. \& İşcan, Ö. F. (2017). Dönüştürücü Liderlik ile İşe Yabancılaşma Arasındaki İlişkide Algılanan Etik İklimin Aracı Rolü. MANAS Sosyal Araştırmalar Dergisi, 6(4), 399-428.

Bass, B. M. (1985). Leadership and Performance Beyond Expectations. Collier Macmillan.

Bass, B. M. \& Riggio, R. E. (2006). Transformational leadership (2nd ed.). Mahwah, NJ: Erlbaum.

Bizzi, L. (2017). Network Characteristics: When an Individual's Job Crafting Depends on the Jobs of Others. Human Relations, 70(4), 436-460.

Burns, J. M. (1978). Leadership. New York: Harper \& Row.

Cavazotte, F., Moreno, V. \& Bernardo, J. (2013). Transformational Leaders and Work Performance: The Mediating Roles of Identification and Selfefficacy. Brazilian Administration Review, 10(4), 490-512.

Dierdorff, E. C. \& Aguinis, H. (2018). Expanding Job Crafting Theory Beyond The Worker and The Job. Management Research: Journal of the Iberoamerican Academy of Management, 16(3), 225-247.

Ding, X., Li, Q., Zhang, H., Sheng, Z. \& Wang, Z. (2017). Linking transformational leadership and work outcomes in temporary organizations: A social identity approach. International Journal of Project Management, 35(4), 543-556.

Eliophotou-Menon, M. \& Ioannou, A. (2016). The Link Between Transformational Leadership and Teachers' Job Satisfaction, Commitment, Motivation To Learn and Trust in The Leader. Academy of Educational Leadership Journal, 20(3), 12-22. 
ElKordy, M. (2013). Transformational Leadership and Organizational Culture as Predictors of Employees Attitudinal Outcomes. Business Management Dynamics, 3(5), 15-26.

Getachew, D. S. \& Zhou, E. (2018). The Influences of Transformational Leadership on Collective Efficacy: The Moderating Role of Perceived Organizational Support. The International Journal of Organizational Innovation, 10(4), 7-15.

Grant, A.M. \& Ashford, S.J. (2008). The Dynamics of Proactivity at Work. Research in Organizational Behavior, 28, 3-34.

Hetland, J., Hetland, H. Bakker, A. B. \& Demerouti, E. (2018). Daily Transformational Leadership and Employee Job Crafting: The Role of Promotion Focus. European Management Journal, 36, 746-756.

Iqbal, Q. (2016). Organizational Politics, Transformational Leadership and Neglect in Banking Sector. International Journal of Management, Accounting and Economics, 3(10), 609-622.

Kerse, G. (2017). İş Becerikliliği (Job Crafting) Ölçeğini Türkçe'ye Uyarlama ve Duygusal Tükenme İle İlişkisini Belirleme. Journal of Business Research, 9(4), 283-304.

Kerse, G. (2018). The Impact of Job Crafting on PersonJob Fit: "I am Compatible With My Work Because I Can Make Changes in My Work. Atatürk Üniversitesi İktisadi ve İdari Bilimler Fakültesi Dergisi, 32(4), 941-958.

Krishnan, V. R. (2012). Transformational Leadership and Personal Outcomes: Empowerment as Mediator. Leadership \& Organization Development Journal, 33(6), 550-563.

Ladan, S., Nordin, N. B. \& Belal, H. M. (2017). Influence of Transformational Leadership on Knowledge Hiding: Mediating role of Organizational Psychological Ownership. International Journal of Business and Management Science, 7(2), 261-277.

Mäkikangas, A. (2018). Job Crafting Profiles and Work Engagement: A Person-Centered Approach. Journal of Vocational Behavior, 106, 101-111.

Miller, M.L. (2015). Relationships Between Job Design, Job Crafting, Idiosyncratic Deals, and Psychological Empowerment (Yayınlanmış Doktora Tezi) Walden University, College of Management and Technology: Minneapolis.

Morgan, G. A., Leech, N. L., Gloeckner, G. W. \& Barrett, K. C. (2004). SPSS for Introductory Statistics: Use and Interpretation. New Jersey: Lawrence Erlbaum Associates Publishers.

Muchiri, M.K., McMurray, A.J., Nkhoma, M. \& Pham, H.C. (2019). How Transformational and Empowering
Leader Behaviors Enhance Workplace Safety: A Review and Research Agenda. The Journal of Developing Areas, 53(1), 257-265.

Nazim, F. \& Mahmood, A. (2016). Principals' Transformational and Transactional Leadership Style and Job Satisfaction of College Teachers. Journal of Education and Practice, 7(34), 18-22.

Reuvers, M., Van Engen, M. L., Vinkenburg, C. J. \& Wilson-Evered, E. (2008). Transformational Leadership and Innovative Work Behaviour: Exploring the Relevance of Gender Differences. Creativity and Innovation Management, 17(3), 227244.

Rita, M., Payangan, O. R., Rante, Y., Tuhumena, R. \& Erari, A. (2018). Moderating Effect of Organizational Citizenship Behavior on The Effect of Organizational Commitment, Transformational Leadership and Work Motivation on Employee Performance. International Journal of Law and Management, 60(4), 953-964.

Salem, I. E.-B. (2015). Transformational Leadership: Relationship to Job Stress and Job Burnout in FiveStar Hotels. Tourism and Hospitality Research, 15, 240-253.

Schmitt, A., Den Hartog, D. N. \& Belschak, F. D. (2016). Transformational Leadership and Proactive Work Behaviour: A Moderated Mediation Model Including Work Engagement and Job Strain. Journal of Occupational and Organizational Psychology, 89, 588-610.

Slemp, G. R. (2016). Job Crafting. İçinde L.G. Oades, M.F. Steger, A.D. Faveand J. Passmore (Eds.), The Wiley Blackwell Handbook of the Psychology of Positivity and Strengths-Based Approaches at Work (pp. 351-365).UK: John Wiley \& Sons.

Slemp, G. R. \& Vella-Brodrick, D. A. (2013). The Job Crafting Questionnaire: A New Scale To Measure The Extent To Which Employees Engage in Job Crafting. International Journal of Wellbeing, 3(2), 126-146.

Soo Young, J. (2017). Mediating Effect of Social Capital between Transformational Leadership Behavior and Organizational Citizenship Behavior in Hospital Nurses. Journal of Korean Academy of Nursing Administration, 23(5), 558-566.

Tabassi, A. A., Roufechaei, K. M., Bakar, A. H. A. \& Yusof, N. (2017). Linking Team Condition and Team Performance: A Transformational Leadership Approach. Project Management Journal, 48(2), 2238.

Tims, M., Bakker, A. B. \& Derks, D. (2015). Examining Job Crafting from an Interpersonal Perspective: Is Employee Job Crafting Related to the Well-Being of 
Colleagues?, Applied Psychology: An International Review, 64(4), 727-753.

Travaglianti, F., Babic, A. \& Hansez, I. (2016). The Role of Work-Related Needs in The Relationship Between Job Crafting, Burnout and Engagement. SA Journal of Industrial Psychology, 42(1), 1-13.

Van Wingerden, J., Derks, D. \& Bakker, A. B. (2017). The Impact of Personal Resources and Job Crafting Interventions on Work Engagement and Performance. Human Resource Management, 56(1), 51-67.

Wang, H., Wang, X. \& Li, J. (2018). Is New Generation Employees' Job Crafting Beneficial or Detrimental to Organizations in China? Participative DecisionMaking as a Moderator. Asia Pacific Business Review, 24(4), 543-560.

Wang, H.-J., Demerouti, E. \& Le Blanc, P. (2017). Transformational Leadership, Adaptability, and Job Crafting: The Moderating Role of Organizational Identification. Journal of Vocational Behavior, 100, 185-195.

Wang, Y., Zheng, Y. \& Zhu, Y. (2018). How Transformational Leadership Influences Employee Voice Behavior: The Roles of Psychological Capital and Organizational Identification. Social Behavior and Personality, 46(2), 313-322.

Wrzesniewski, A. \& Dutton, J. E. (2001). Crafting a Job: Revisioning Employees as Active Crafters of Their Work. Academy of Management Review, 26(2), 179201.

Wrzesniewski, A., LoBuglio, N., Dutton, J. E. \& Berg, J.M. (2013). Job Crafting and Cultivating Positive Meaning and Identity in Work. Advances in Positive Organizational Psychology, 1, 281-302.

Yukl, G. A. (1994). Leadership in Organizations. Prentice-Hall, Englewood Cliffs, NJ.

Zhang, F. \& Parker, S. K. (2019). Reorienting Job Crafting Research: A Hierarchical Structure of Job Crafting Concepts and Integrative Review. Journal of Organizational Behavior, 40, 126-146. 